\title{
El cooperativismo y la economía solidaria: génesis e historia
}

\author{
Luis Francisco Ramírez-Díaz , José de Jesús Herrera-Ospina ${ }^{* *}$, Luis Fernando Londoño-Franco ${ }^{* * *}$
}

\footnotetext{
Magíster en Ciencias Económicas, Universidad Nacional de Colombia. Profesor investigador asociado, Politécnico Colombiano Jaime Isaza Cadavid, Medellín, Colombia. Correo electrónico: luisramirez@elpoli.edu.co

** Doctor en Filosofía, Universidad Pontificia Bolivariana. Profesor investigador asociado, Politécnico Colombiano Jaime Isaza Cadavid, Medellín, Colombia.

Correo electrónico: jjherrerao@elpoli.edu.co

*** Ph.D en Medicina Animal, Universidad de León de España. Profesor investigador asociado, Politécnico Colombiano Jaime Isaza Cadavid, Medellín, Colombia. Correo electrónico:

Iflondono@elpoli.edu.co
}

Recibido: 20 de marzo del 2016

Aceptado: 31 de mayo del 2016

Cómo citar este artículo: Ramírez-Díaz, L. F., Herrera-Ospina, J. J. y Londoño-Franco, L. F. (2016). El cooperativismo y la economía solidaria: génesis e historia. Cooperativismo \& Desarrollo, 24(109), Xx-Xx. doi: 10.16925/ Co.v24i109.1507

\section{Resumen}

Propósito: el presente artículo presenta una revisión sistemática del pensamiento filosófico sobre los comienzos de la economía solidaria en los contextos internacional y nacional. Descripción: el desarrollo de la economía globalizada exige nuevos escenarios que involucren al pensamiento y a la praxis cooperativa o de economía solidaria en las diferentes actividades que constituyen el quehacer de los seres humanos, es decir, en la política, la sociedad, la economía, la cultura, entre otras. En este artículo se ilustra el desarrollo del cooperativismo y la economía solidaria desde su concepción hasta su aporte al mejoramiento de la calidad de vida de los seres humanos; además de propiciar un escenario adecuado para los enfoques que generan los acuerdos de paz en Colombia. Punto de vista: el artículo trata de dar una mirada al desarrollo teórico, desde las diferentes corrientes surgidas en el transcurso del tiempo, del concepto de economía solidaria como una respuesta a las crisis sociales que han acompañado el trascurrir de la humanidad. Conclusiones: la solidaridad a lo largo de la historia se ha venido constituyendo con base en un desarrollo social que busca la equidad, la justicia y la sostenibilidad de los individuos. La descripción hecha en este artículo nos permite establecer la caracterización del pensamiento solidario como base para el progreso de las comunidades en el contexto actual.

Palabras clave: comunidad, cooperativismo, economía solidaria, humanidad, sociedad. 


\title{
Cooperativism and the solidarity economy: origin and history
}

\begin{abstract}
Purpose: This article presents a systematic review of philosophical thought about the beginnings of the solidarity economy in the international and national context. Description: The development of the global economy requires new settings for thinking and the praxis of cooperativism or solidarity economies in the different activities that constitute the work of human beings, i.e., politics, society, economics, and culture, among others. This article describes the development of cooperativism and the solidarity economy from their conception to their contribution to the improvement of the quality of life of human beings, in addition to providing a suitable setting for the approaches generated by the peace agreements in Colombia. Viewpoint: The article attempts to consider theoretical development from the different schools of thought that have arisen over time, from the concept of the solidarity economy as a response to the social crises that have accompanied civilization. Conclusions: Solidarity has historically been based on social development that seeks equity, justice, and sustainability for individuals. The description provided in this article allows us to establish the characterization of thinking about solidarity as a basis for the progress of modern communities.
\end{abstract}

Keywords: community, cooperativism, solidarity economy, humanity, society

\section{O cooperativismo e a economia solidária: gênese e história}

\section{Resumo}

Propósito: o presente artigo apresenta uma revisão sistêmica do pensamento filosófico sobre os começos da economia solidária nos contextos internacional e nacional. Descrição: o desenvolvimento da economia globalizada exige novos cenários que envolvam o pensamento e a práxis cooperativa ou de economia solidária nas diferentes atividades que constituem o trabalho dos seres humanos, isto é, na política, na sociedade, na economia, na cultura, entre outras. Neste artigo ilustra-se o desenvolvimento do cooperativismo e da economia solidária desde sua concepção até sua contribuição para a melhoria da qualidade de vida dos seres humanos; além disso, propiciar um cenário adequado para os enfoques que geram os acordos de paz na Colômbia. Ponto de vista: o artigo tenta apresentar o desenvolvimento teórico, a partir das diferentes correntes surgidas no transcurso do tempo, do conceito de economia solidária como uma resposta às crises sociais que acompanharam o transcurso da humanidade. Conclusões: a solidariedade ao longo da história veio-se constituindo com base num desenvolvimento social que procura a equidade, a justiça e a sustentabilidade dos indivíduos. A descrição feita neste artigo permite-nos estabelecer a caracterização do pensamento solidário como base para o progresso das comunidades no contexto atual.

Palavras-chave: comunidade, cooperativismo, economia solidária, humanidade, sociedade. 


\section{Introducción}

El cooperativismo, por el tamaño y amplitud de su movimiento, representa posiblemente la forma de organización socioeconómica de carácter universal más grande del mundo. Han sido más de 167 años de historia desde su nacimiento oficial. No obstante, es menester anotar que, desde el comienzo de las organizaciones sociales, los seres humanos han cooperado, especialmente para defenderse de las fuerzas de la naturaleza y de otros animales, buscar dominio territorial, preservar la existencia y fortalecerse, entre otras. ${ }^{1}$

Desde este punto de vista, es importante mencionar algunas manifestaciones de cooperación en la historia antigua: los Undestabings ${ }^{2}$ en Babilonia, para el intercambio de productos agrícolas; las sociedades de beneficio, para el culto de los muertos en Atenas; los llamados Collegia ${ }^{3}$, en Roma, que ejercían una actividad comercial conjunta.

En nuestro territorio, cabe anotar que en las organizaciones indígenas no existía la propiedad privada. Los mayas, aztecas, y los incas realizaban el trabajo colectivo con medidas de previsión. Con la llegada de los europeos se presentó una nueva cultura de la cooperación basada en aspectos religiosos, particularmente basada en el cristianismo católico (en el caso de la América luso-hispana) y el protestante (en el caso de la América galo-anglosajona).

Por otra parte, la Revolución industrial afianza el capitalismo y es en este contexto (hacia 1844) en el que se crea la cooperativa de los pioneros de Rochdale como soporte para el desarrollo social de los trabajadores. Los primeros principios del cooperativismo representaron un esfuerzo propio, así como la libertad,

\footnotetext{
1 A propósito, se pueden rastrear los estudios de especialistas en la materia tales como Cliford Geertz, Desmond Morris, Charles Taylor, entre otros. A saber, Conocimiento local: ensayos sobre la interpretación de las culturas; el mono desnudo, y El multiculturalismo y "la política del reconocimiento".

2 Este término proviene del vocablo alemán stab que significa "vara, palo, varilla", y hace referencia a las formas de intercambio que se tenían en ese momento histórico de la humanidad.

3 Los Collegia (plural de Collegium) eran las instituciones romanas que tenían un papel fundamental en el derecho romano. Representaban las asociaciones privadas que ayudaban económicamente a las personas a las cuales el Estado romano no alcanzaba a proteger.
}

la ayuda mutua, la ausencia de ánimo de lucro, la democracia y el deseo de superación (Lambert, 1961).

\section{Orígenes de la economía solidaria y el cooperativismo}

Los hombres primitivos eran cooperadores por naturaleza y tanto el trabajo como sus frutos, incluyendo los bienes necesarios para obtenerlos, eran un asunto colectivo. La literatura reporta que en Egipto los artesanos de los faraones tenían un comercio altamente desarrollado, lo cual llevó a la conformación de asociaciones encargadas de la regulación de las actividades para amparar los intereses comunes. En las sociedades griegas (como Atenas) y romanas del siglo v a. C. al siglo iII d. C. existía una estrecha relación de cooperación entre agricultores y artesanos representada por las sociedades de beneficios mutuos y el culto de los muertos. También en Babilonia, hacia el 550, aparecieron los Undestabings cooperativos, orientados al intercambio y la comercialización de productos agrícolas. De igual forma, en China, en el siglo XII surgieron asociaciones cooperativas de ahorro y crédito en la dinastía Chou.

En la América precolombina sobresalieron los mayas, aztecas e incas, quienes dieron mayor valor a la propiedad y el trabajo colectivo combinados con la propiedad familiar y el trabajo individual. En estas sociedades existían medidas de previsión social fortalecidas por la solidaridad.

En 1590, durante el dominio español, la corona creó los Resguardos indígenas, o tierras comunitarias, como una encomienda ${ }^{4}$ para catequizar y proteger a los nativos de la esclavitud (una política totalmente contradictoria). En estos resguardos los indígenas podían explotar la tierra y residir en ella, aunque no tenían ningún derecho de propiedad sobre esta. Asimismo, se creó la mita, ${ }^{5}$ que representó

La encomienda es una institución socioeconómica, surgida durante el período de colonización española en América, que buscaba que un grupo de individuos retribuyeran a otro en trabajo, especie, o por otro medio, por disfrutar de un bien o una prestación (préstamo) que se hubiese recibido.

5 La mita buscaba que el trabajo del indígena sirviera al Estado aborigen como una forma de protección contra las guerras y una forma de progreso de la sociedad en la consecución de fines comunes como la construcción de alcantarillados, viviendas, entre otras cosas. Hay que anotar que este trabajo era de carácter obligatorio. 
una institución tradicional de las sociedades indígenas para la colaboración comunitaria.

De igual forma, en Colombia, los indígenas paeces y guambianos desarrollaron la minga ${ }^{6}$ (mano prestada), como una figura de ayuda o colaboración entre las familias o miembros de la misma tribu (Lambert, 1961).

En el siglo XVIII, se dan los primeros inicios del cooperativismo en Nueva Holanda (EE.UU.). Con la creación de la cooperativa americana por Pleckhoy, en 1730, se introduce un sistema de participación en las pesquerías de Nueva Inglaterra (EE.UU.). Seguidamente, en 1750, nace la sociedad mutual contra incendios en Estados Unidos. En 1816 se crea el primer banco de ahorro mutuo (EE.UU.).

Es importante resaltar que, en este momento de la historia, los grandes acontecimientos que ayudaron a sentar las bases del cooperativismo fueron la Revolución francesa (con sus aportes en el campo social y su forma de pensar en justicia, libertad, equidad y racionalidad científica) y la Revolución industrial (empoderada en la tecnología, las nuevas formas de energía y una fuerte demanda de conocimiento sobre propiedades, sustancias, mercancías y materiales). Esta última contribuyó a fomentar el capitalismo y el ánimo de lucro.

Asimismo, es relevante la influencia de los pensadores sociales e intelectuales de la época en la aparición de la economía solidaria. Dicha influencia se puede ver en los cambios sociales y económicos señalados por David Ricardo, la teoría de valor del laissez faire, los factores de producción de Adam Smith, la relación entre capital y empresario de J. B. Say, e incluso en la iniciativa de construcción de un nuevo tipo de sociedad de C. Marx y F. Engels. En última instancia, la iglesia, a través de su doctrina, también tuvo influencia en los cambios sociales de la humanidad (Birnie, 1965; Mladenatz, 1980; Edelmann, 1992, 121).

Minga es un término de la comunidad indígena quechua que significa "construcción colectiva". Dado que las sociedades indígenas tienen una visión del mundo integral, cosmogónica, unificada a través sus mitos y realidades históricas, la minga se convierte en una construcción de la vida social que lleva a la búsqueda del encuentro intersubjetivo con miras a resolver problemas propios de la comunidad. La minga se practicó como como forma solidaria en las culturas indígenas en el territorio que hoy es Suramérica (sur de Colombia, Ecuador, Perú, Bolivia, Chile y Paraguay).

\section{Precursores del cooperativismo}

\section{Contexto: las causas socioeconómicas, políticas y culturales de la Revolución industrial en Inglaterra y la Revolución francesa}

Sin lugar a dudas, el contexto histórico en el que se desarrollaron las ideas que se presentan en el cooperativismo tienen que ver con dos acontecimientos fundamentales: la Revolución francesa, que tiene su cénit en 1789, y la Revolución industrial en Inglaterra. Los inicios del siglo XVII nos presentan una nueva época moderna como un tiempo de revoluciones, cambios y nuevas perspectivas socioeconómicas, políticas y culturales de gran importancia. Sucintamente, destaquemos de estas dos revoluciones unos elementos comunes. En primer lugar, las ideas de libertad y progreso. La Edad Media había generado un importante malestar político que se generalizó en la sociedad. En ella, la monarquía era la única forma de poder político (y las figuras del papa y del emperador, sumadas a la famosa teoría de la doble espada). En lo económico, el régimen del feudalismo hacía ver un despotismo o tiranía, dado que la concentración de las tierras en manos de un solo señor o amo daba una omnipotencia absoluta al señor feudal que no permitía ni libertad ni progreso tanto para el ser humano (siervo o plebeyo) como para la sociedad que, siendo en su mayor parte agrícola, esperaba mejores retribuciones económicas. El ascenso, pues, de la burguesía y de una clase proletaria dueña de sus tierras, casas o lugares de trabajo, fue generando lo que se terminó de construir con la Revolución industrial en un primer momento y luego con la Revolución francesa: la nueva formulación de un Estado moderno con libertad tanto en lo económico como en lo político. En segundo lugar, se da un cambio cultural en la Modernidad en comparación con la Antigüedad y el Medioevo. Se respira un clima de interculturalidad del que, si bien en las épocas pasadas hubo ciertos atisbos, es la Modernidad la que nos da las mejores muestras. Los descubrimientos geográficos de América, Asia, Oceanía; lo científico-tecnológico; las reformas religiosas, entre otras más, hacen de esta época una era sin precedentes. En esta, los precursores del cooperativismo van a desempeñar un papel fundamental con sus propuestas en este contexto. Es menester, pues, hacer alusión a los teóricos del cooperativismo en Europa, al menos desde los siglos XVIII y xIX. 


\section{Robert Owen}

Sin lugar a dudas, el teórico más importante del cooperativismo ha sido el inglés Robert Owen, nacido en 1771 y muerto en 1858 , quien propuso el término de comunidades autónomas. Owen vivió en carne propia las consecuencias de la Revolución industrial, que tuvo lugar en Inglaterra a finales del siglo xviII y pronto se preocupó por el destino de la humanidad en estos nuevos escenarios económicos, políticos sociales y culturales. Se preocupaba, sobre todo, porque esta revolución presuponía, en la mayoría de los casos, una concepción del hombre como máquina para el trabajo y dejaba a un lado la dignidad de la persona humana, la cual está hecha, no para el trabajo sin freno, sino para el trabajo moderado y digno. Pensó Owen una alternativa para contrarrestar este fenómeno y dio con la idea del trabajo asociado, la cooperativa. En su origen, la idea de Owen se basaba en que es posible desarrollar un sistema económico alternativo que sustituyera el sistema económico que empezaba a ser imperante y avasallador: el capitalismo. Las cooperativas pasarían a ser grupos humanos de trabajo asociado con calidad de vida para sus integrantes (comunidades autónomas). Es importante indicar que las industrias creadas hasta el momento exigían que un trabajador asalariado o proletario dedicara más de 16 horas de trabajo (incluso hasta 20 horas) a la producción de productos o servicios, dejando para su descanso un escaso número de horas. La idea de Owen tuvo tanto eco que muy rápidamente se constituyeron por toda Inglaterra más de 500 cooperativas. Logrando éxito cuando se asumió la defensa de los derechos del trabajador, incitó al trabajo en común y motivó con sus ideas y propuestas a las nacientes asociaciones de obreros ingleses. No obstante, como todo pensador, tuvo sus detractores, los cuales vieron en este tipo de organización un peligro para el nacimiento de un sistema económico que dominaría el mundo (Pineda, 1994).

\section{William King}

King nace en Brighton, Gran Bretaña, en 1786 y muere en 1865. Es compañero de lucha de Robert Owen. También fue testigo de la deshumanización de los obreros y trabajadores con el trato dado a ellos por sus patronos. En su época hubo grandes crisis económicas que dieron lugar a despidos masivos, los cuales afectaban de manera enorme la calidad de vida de los trabajadores y, lógicamente, la de sus familias. Su propuesta se encaminó a la creación de cooperativas de consumo que pudieran ser un paliativo a la situación de crisis que vivían las personas asalariadas. Además, propuso crear cooperativas de producción en las que la actividad fundamental recaía en la figura de los trabajadores asociados. Lógicamente, esto debería tener como base la adquisición del capital por parte del trabajador, cosa que se consideraba utópica, pero, según King, no era imposible ya que, como el mismo dice: "El trabajador al carecer de capital, se ve obligado a vender su trabajo a quien es poseedor de aquel; sin embargo, el trabajador podría fácilmente convertirse en propietario del capital, porque todo capital es producto del trabajo" (Diccionario de Economía Social, 2009, p. 188).

Con base en estas ideas se crearon tiendas cooperativas en las que los artículos se vendían de acuerdo al principio de reciprocidad asociativa. Estas tiendan comerciaban al por menor y no al por mayor, como posteriormente lo haría este tipo de comercio. King, no obstante, fue el propulsor de que se pudiera comprar y vender al por mayor, aunque, como dijimos, esto tendría su realización años después, de tal modo que con ello se perdió la idea de cooperativa de asociación con reciprocidad. La primera cooperativa de este tipo fue creada por King, en 1828 en su ciudad natal. Además, King fue un gran impulsor de cooperativas de magacines literarios, periódicos y otras actividades que redundaron en la construcción del trabajo asociado para su época (Pineda, 1994).

\section{Philllippe Buchez}

Buchez fue un inspirador francés del movimiento cooperativo, nació en Montagne-la-Petite en 1796 y murió en Rodez en 1865. Desde muy joven se interesó por los movimientos de izquierda y por la masonería. Fundó una logia masónica, junto con otros compañeros, llamada "los Amigos de la verdad”. Se sublevó contra los borbones al este de Francia, pero con poco éxito. Posteriormente, fundó la Carbonería Francesa, la cual llegó a contar con 80000 miembros. Inició así un trabajo social que lo llevó después a fundar organizaciones sociales con una mirada cooperativa. Se dedicó al estudio de la medicina y escribió artículos importantes sobre este tema y su relación con la sociedad, especialmente la de la higiene. La influencia de Saint Simon y su obra El nuevo cristianismo hizo que se inclinara por este pensamiento religioso. No obstante, se desencantó de esta escuela para 
volver de nuevo a las huestes católicas, pero trató de conciliar el catolicismo con las nuevas teorías políticas del socialismo; de ahí que se le considere un socialista cristiano. Por la misma época fundó las primeras cooperativas de trabajo en Francia, las cuales tenían como base fundamental a la clase obrera y se oponían a las creadas por Owen en Inglaterra, de corte marcadamente comunista, y a las de Saint Simon, de corte industrial. Las primeras cooperativas tuvieron corta duración y solo permanecieron las de joyeros hasta 1873. La época de mayor producción literaria de Buchez fue entre 1833 y 1850 , periodo en el que planteó la reforma social basada en la asociación obrera, la cual debería reunir un capital que permitiera la consolidación económica de la clase obrera a nivel global. Su carrera política fue un total fracaso. Luego de ser elegido como representante del departamento del Sena a la Asamblea Nacional, de la cual llegó a ser presidente por solo ocho días, le tocó vivir las arremetidas violentas del ejército y la guardia nacional contra los obreros que dejaron centenares de muertos. Manifestó su inconformidad con los gobernantes de turno frente estos hechos. Se opuso particularmente al gobierno de Luis Napoleón Bonaparte, por lo que fue arrestado. Sus últimos años de vida los dedicó al estudio y a la redacción de un tratado sobre política y ciencia social. Sus restos mortales reposan en el cementerio Père Lachaise en París (Oviedo, 2007).

\section{François Marie Charles Fourier}

Francés, nacido en Besanzón el 7 de abril de 1772 y fallecido en París el 10 de octubre de 1837, es una de las figuras más importantes del socialismo moderno. Fue un crítico acérrimo del capitalismo y de la economía de mercado. Observó en los procesos de industrialización moderna la degradación total del hombre y en el imaginario cultural basado en la religión y moral cristianas la condena del ser humano a la infelicidad. La concepción de pecado original era para él una degradante mirada de la condición humana, pues ponía el sufrimiento del hombre como garante de una futura salvación. Fourier consideraba que el hombre debía buscar su felicidad en aquello que le procurará placer y satisfacción personal. Así, la búsqueda de la felicidad personal y de la sociedad debería estar basada en una cooperación mutua, en una búsqueda de colaboración interpersonal, y en una ampliación de las relaciones sociales (incluso sexuales y afectivas) que evite tanto la monotonía como el conformismo.

Fourier consideraba que las pasiones son impulsos y necesidades que el hombre podía desarrollar para el bien de sí mismo y de su comunidad. Claro está, no podrían ser pasiones desenfrenadas y caóticas, sino mediadas por la armonía. Esto llevaba a la defensa del libre desarrollo de la personalidad a través de la armonía de las pasiones, la cual se logra a partir de un modelo distributivo para la superación de los conflictos que se generan en la sociedad.

Sus ideas lo llevaron a ser pionero del cooperativismo basado en la creación de pequeñas comunidades o falansterios en los que los beneficios económicos obtenidos deberían ser repartidos entre sus miembros. Hizo todo lo posible para lograr que dueños del capital asintieran a estas ideas cooperativas, no obstante, no tuvo mucha acogida.

Fourier es un predecesor de las ideas del socialismo libertario que tiene como objeto formar asociaciones voluntarias con base en un sistema político distinto al liberalismo y en un sistema económico distinto al capitalismo. Términos como "consejo obrero", "comunidad autónoma", "principio federativo" fueron creación suya y posteriormente fueron utilizados tanto en la economía como en la política.

No sacrifiquen la felicidad de hoy a la felicidad futura. Disfruten del momento, eviten toda unión de matrimonio o de interés que no satisfaga vuestras pasiones desde el mismo instante. ¿Por qué van a luchar por la felicidad futura, si ella sobrepasará vuestros deseos, y no tendrán en el orden combinado más que un solo displacer, el de no poder doblar la longitud de los días, a fin de dar abasto al inmenso círculo de goces que deberán recorrer? (Oviedo, 2007).

\section{Louis Blanc}

Louis Blanc, nacido en 1811 y muerto en 1882, fue, al igual que Fourier, un pensador y político francés, aunque realmente nació en Madrid (España). Debido a que la península Ibérica estaba supeditada al poder político de los franceses, en particular por José I (de la dinastía de los Bonaparte), se le considera francés; además, murió en la ciudad de Cannes.

Su libro más importante es "La organización del trabajo", publicado en 1839. En él realiza una crítica al pensamiento burgués y capitalista de su tiempo, adelantándose a Marx (a quien dedicaremos la segunda parte de este artículo). Él propuso que el Estado debía 
actuar e intervenir en la sociedad para ayudar a superar las desigualdades sociales y proponía, en concreto, "unas cooperativas obreras que organizaran democráticamente cada rama de la producción, repartiendo igualitariamente sus beneficios y suministrando pensiones de vejez y enfermedad" (Biografías y vidas, 2004-2016; 2012, p. 79).

Blanc contribuyó, también, a la caída de Luis Felipe de Orleans con las críticas expresadas en su obra Historia de diez años, publicada en 1831. Tras la Revolución parisina, que en 1848 instauró la llamada Segunda República, accedió al poder gubernamental, siendo nombrado ministro de trabajo. Impulsó, durante su gestión en esta cartera, los "talleres nacionales" para ayudar un poco a salir de las crisis económicas existentes, pero estos fueron un total fracaso, lo que le llevó al exilio en Bélgica e Inglaterra. Su estadía en Inglaterra le permitió conocer de primera mano materiales importantes de la Revolución industrial que llevaría a fundamentar su libro "Historia de la Revolución", publicado en 1848.

Regresó a Francia en 1859, accedió a muchos cargos públicos, se caracterizó por su defensa a los comuneros, su lucha por la abolición del senado corrupto y la búsqueda de un nuevo sistema político. $\mathrm{Su}$ muerte, acaecida en 1882, se aceleró por la muerte de su esposa, a quien amaba entrañablemente, en 1876. Sus restos se encuentran en el famoso cementerio parisino Père Lachaise (Oviedo, 2007).

\section{Charles Gide}

Es considerado un científico social. Nació en Francia en 1847 y murió en 1932. Fue profesor de economía política y en sus cargos sobresale el de representante del cooperativismo francés en diversos congresos internacionales.

Uno de sus principales méritos fue consolidar las bases y doctrinas para posicionar la cooperativa Rochdale. Gide propició la unidad del cooperativismo francés, aconsejó sobre los colores de la bandera multicolor adoptada por el cooperativismo mundial, fundó la escuela de Nimes que difundió su pensamiento. De igual manera, sistematizó las reglas del cooperativismo inglés, especialmente de Rochdale, y redactó diversos libros y publicaciones relacionadas con la economía solidaria y el cooperativismo.

Su programa de cooperativismo planteó el desarrollo por etapas. Inicialmente, se debían establecer los almacenes de consumo (conquista de la industria comercial). Posteriormente, era necesario producir todo lo que fuera requerido por la sociedad en su conjunto (conquista de la industria empresarial). Finalmente, se debía dominar la producción agrícola (conquista de la industria agrícola).

Entre sus citas célebres podemos recordar: "Les mostraré un fin inmediato y presente: la educación económica de la clase obrera por la asociación cooperativa; y un fin más distante: la emancipación de la clase operaria por la transformación del salario" y "Oh pioneros de Rochdale ustedes han desarrollado el único experimento social exitoso del siglo xIx. Es así que la fe de ustedes ha dado prueba de un poder creador mayor que toda la ciencia de los economistas" (Citado por Lambert, 1961, p. 309).

\section{Pioneros de Rochdale}

En Rochdale, Inglaterra, en 1844, gracias a la convicción de 28 humildes líderes tejedores, se creó la primera cooperativa que recibió el máximo reconocimiento institucional en su momento. Esta surge debido a la necesidad crítica, resultado de los bajos salarios y de la desocupación obrera.

La cooperativa, alimentada por el inconformismo con el sistema capitalista de la época, propicia que los pioneros de Rochdale pongan en práctica el rescate de la justicia social. No hablaban, sin embargo, de paraísos en los que no se tuviera que trabajar, ni tampoco creían en lugares maravillosos en los que no se conociera el dolor ni la enfermedad. Los pioneros eran idealistas, pero, al mismo tiempo, eran realistas (Rojas, 1952).

Los pioneros se inspiraron en los pensadores Robert Owen y William King y quisieron sobreponerse al fracaso de las acciones paternalistas, religiosas o sociales anteriores a ellos, replanteando su accionar hacia la acción económica y social autónoma e independiente.

Uno de los principios del programa de los pioneros fue establecer que la sociedad tiene por fin obtener un beneficio pecuniario y mejorar las condiciones domésticas y sociales de sus miembros por medio del ahorro. Además, el programa contenía reglas y principios teóricos muy prácticos, sencillos para la vida cotidiana, aceptados por el común de los ciudadanos y de fácil cumplimiento.

El éxito alcanzado por la cooperativa inglesa de Rochdale se fundamenta en el cooperativismo de consumo, pero se complementa posteriormente con la teoría francesa de la cooperación de la producción y con las célebres enseñanzas de los alemanes 
generadores de las cooperativas de ahorro y crédito. De este entrecruce nació un nuevo sistema que, sin pretensiones ni superioridad con respecto a otros movimientos sociales, se encaminó por la paz, la ayuda mutua y la solidaridad. Este sistema, por medio de reglas sencillas y prácticas, señaló una ruta cooperativista al mundo entero (Uribe, 1993).

Consecuentemente, los pioneros desarrollaron los siete principios cooperativos rochdalianos (adhesión libre, control democrático, devolución o bonificación sobre las compras, interés limitado al capital, neutralidad política y religiosa, ventas al contado y fomento de la enseñanza), principios sabiamente seleccionados, reunidos y aplicados. Estos han prevalecido en el tiempo, se han vuelto universales y aplicables en el diseño y desarrollo de cooperativas a través del mundo (Mladenatz, 1980).

\section{Alianza Cooperativa Internacional (ACI)}

Después de Rochdale, en 1869, se realizó un congreso británico de cooperativas que planteó la necesidad de establecer un marco doctrinario que orientara la acción cooperativa para tener un modelo asociativo e integral que armonizara las funciones cooperativas y sus miembros. Este congreso contribuye al nacimiento de la Asociación Internacional de Cooperativas (ACI). Su agenda se mantuvo vigente hasta cuando se celebraron los congresos de la ACI en 1895 (Londres), 1896 (París), y en 1924 (Gand). No obstante, la ACI mantuvo los principios originales rochdalianos con leves reformas, entre ellas, la devolución sobre las compras, llamándose distribución de excedentes, a los asociados en proporción a las operaciones con la cooperativa. También en el congreso de Paris dividieron los principios en Esenciales y Recomendados (Parrilla, 1989).

\section{Principios cooperativos de 1937, congreso de ACI (París)}

En este congreso quedan sentadas las bases doctrinarias de los principios cooperativos que consolidaron el cooperativismo mundial. Los principios esenciales fueron: adhesión libre, control democrático, distribución de excedentes en proporción a las operaciones, interés limitado al capital. Por su parte, los principios recomendados fueron: neutralidad política, religiosa, ventas al contado y fomento de la enseñanza.

Es importante señalar que en sus más de 150 años el cooperativismo ha pasado por tres etapas de crecimiento y cambio en las cuales también se han presentado crisis como la de credibilidad, que se dio desde los orígenes del cooperativismo moderno. La segunda crisis se presentó por la deficiencia en la capacidad administrativa y la falta de gestión. La tercera crisis se originó por un pensamiento general acerca de la ideología o el verdadero propósito del papel del cooperativismo en el mundo competitivo, capitalista y su clara diferenciación respecto a otras empresas (Laidlaw, 2000).

\section{Karl Marx y el cooperativismo}

\section{Semblanza e inicios}

Karl Heinrich Marx nació en Tréveris (Reino de Prusia) en 1818 y murió en Londres el 14 de marzo de 1883. Fue un filósofo, intelectual y partidario del partido comunista alemán de origen judío. Su vasta obra influyó en la historia, la economía, la sociología, la ciencia política del siglo xIX y de los siglos venideros. Es considerado un verdadero intelectual que no solo ejerció el pensamiento en sentido abstracto, sino que lo llevó a la práctica tanto en lo social como en lo político. Sus ideas sobre la revolución del proletariado llevarían, en el siglo xx, a dos grandes hitos en la historia de la humanidad: la Revolución Bolchevique en Rusia, con Vladimir Ilich Ulianov, más conocido como Lenin, y la Revolución Comunista en China con Mao Zedong.

Nos interesa, sin embargo, más que su perfil biográfico, que sería extenso, detallar su pensamiento sobre el tema del cooperativismo. A continuación, presentamos algunos extractos de sus ideas al respecto, tomadas del Manifiesto inaugural de la asociación internacional de los trabajadores (Londres, 1864):

Nos referimos al movimiento cooperativo, y, sobre todo, a las fábricas cooperativas creadas, [...] Es imposible exagerar la importancia de estos grandes experimentos sociales que han mostrado con hechos, no con simples argumentos, que la producción en gran escala y al nivel de las exigencias de la ciencia moderna, puede prescindir de los patronos, que utiliza el trabajo de la clase de las «manos»; han mostrado también que no es necesario para la producción, que los instrumentos de trabajo estén monopolizados como instrumentos de dominación y de explotación contra el trabajador mismo y han mostrado, por fin, qué es el trabajo esclavo, qué el trabajo siervo y el trabajo asalariado. En resumen es una forma transitoria de trabajo inferior, destinada a desaparecer ante el trabajo aso- 
ciado, que sí cumple su tarea con gusto, entusiasmo y alegría (Marx, 1884, Tomo I, p. 115).

Al mismo tiempo, las experiencias del período comprendido entre 1848 y 1864 han probado hasta la evidencia que, por excelente que sea en principio, por útil que se muestre en la práctica, el trabajo cooperativo, limitado estrechamente a los esfuerzos accidentales y particulares de los obreros, no podrá detener jamás el crecimiento en progresión geométrica del monopolio, ni emancipar a las masas, ni aliviar siquiera un poco la carga de sus miserias. Este es, quizá, el verdadero motivo que ha decidido a algunos aristócratas bien intencionados, a filantrópicos charlatanes, burgueses y hasta a economistas agudos, a colmar de repente de elogios nauseabundos, al sistema cooperativo, que en vano habían tratado de sofocar en germen, ridiculizándolo como una utopía de soñadores o estigmatizándolo, como un sacrilegio socialista. Para emancipar a las masas trabajadoras, la cooperativa debe alcanzar un desarrollo nacional $y$, por consecuencia, ser fomentada por medios nacionales. Pero los señores de la tierra y los señores del capital se valdrán siempre de sus privilegios políticos para defender y perpetuar sus monopolios económicos. Muy lejos de contribuir a la emancipación del trabajo (Marx, 1884, Tomo I, p. 123).

\section{Textos básicos de El capital}

En la obra de Marx encontramos referencias muy claras al cooperativismo. En su obra fundamental El capital, particularmente en el capítulo xiII, se encuentran los puntos más importantes de su reflexión sobre el tema que nos concierne. Extraemos algunos apartes que nos ayudarán a comprender la importancia del tema para el siglo XIX, como también para nuestra época:

Cuando varios trabajadores funcionan juntos hacia un objetivo común en el mismo proceso de producción o en procesos distintos, pero conexos, su trabajo adopta la forma cooperativa. [...] No se trata únicamente de aumentar las fuerzas productivas individuales, sino de crear por medio de la cooperación, una nueva fuerza, que funcione como fuerza colectiva (Marx, 1970, pp. 323-324.).

La cooperación permite agrandar el espacio en que se desarrolla el trabajo [...] De igual forma amplía la escala de producción, permite reducir el espacio en que se ejecuta el proceso de trabajo. Ese doble efecto, tan potente palanca en la economía de los faux frais (falsos costos), se debe nada más que a la asociación de los trabajadores, a la aproximación entre sí de operaciones distintas, pero conexas, y a la concentración de los medios de producción [...] Al actuar en un objetivo común y según un plan concertado, el trabajador borra los límites de su individualidad y desarrolla su potencia como especie. [...] La concentración de los medios de producción en manos de capitalistas individuales es, entonces, la condición material de cualquier cooperación entre asalariados (Marx, 1970, pp. 326-327).

En los comienzos del capital, su mando sobre el trabajo tiene un carácter puramente formal y accidental. El obrero no trabaja entonces a las órdenes del capital, como no sea, porque le vendió su fuerza. Sólo trabaja para él, porque no posee los medios materiales para hacerlo por su propia cuenta. Pero en cuanto hay cooperación entre obreros asalariados, el dominio del capital se desarrolla como una necesidad para la ejecución del trabajo, como una condición real de producción (Marx, 1970, p. 328).

Como personas independientes, los obreros son individuos aislados que entran en relación con el mismo capital, pero no entre sí. Su cooperación comienza en el proceso de trabajo, pero en ese momento han dejado de pertenecerse. En cuanto ingresan están incorporados al capital. En la medida en que cooperan, en cuanto son los miembros de un organismo activo, se vuelven un modo particular de existencia del capital. La fuerza productiva que los asalariados despliegan al funcionar como trabajador colectivo es, por lo tanto, fuerza productiva del capital (Marx, 1970, p. 330).

Así como la potencia colectiva del trabajo desarrollada por la cooperación, aparece como forma productiva del capital, la cooperación se presenta como modo específico de la producción capitalista. Esa es la primera fase de transformación que recorre el proceso de trabajo a consecuencia de su subordinación al capital. Esta transformación se desarrolla de manera espontánea. [...] El modo de producción capitalista se presenta, pues, como necesidad histórica, para transformar el trabajo aislado en trabajo social. Pero en manos del capital, esa socialización del trabajo sólo aumenta sus fuerzas productivas para explotarlo con mayor ganancia (Marx, 1970, p. 332). 


\section{El cooperativismo y la economía solidaria en el desarrollo nacional colombiano}

\section{Aspectos generales}

La llegada del modelo asociativo sustentado en la ayuda mutua, la cooperación y la solidaridad tiene un significado especial tanto para el continente Americano como para Colombia, al influir en las costumbres de las comunidades indígenas y la afrocolombianas, tal como lo vimos al inicio de este artículo, una historia de trabajo comunitario reconocido posteriormente por la historia (Funedas, 2012, p. 37).

A la llegada de los españoles, las culturas más desarrolladas eran la Tairona y la Muisca:

Tenían grandes aldeas, densamente pobladas, agricultura muy adelantada por sus técnicas y sus cultivos en terraza, cerámica y textiles, desarrollaban un activo comercio, la sociedad organizada en sectores bien diferenciados por la riqueza o por el oficio, y un gran adelanto político ya que los cacicazgos se unían o estaban en vías de formar grandes confederaciones (Funedas, 2012).

La producción, resultado de estas relaciones, era netamente social y las relaciones eran de protección, de culturización y de dominación. Los negros que escapaban de sus opresores formaron palenques en donde los cimarrones (nombre que recibieron los esclavos escapados) producían en forma comunitaria, de forma que imperaba la cooperación.

Como cada época trae sus problemas, y con ellos también viene la preocupación de estudiosos para poder resolverlos, en Colombia, en 1899, se crearon las “sociedades de socorro mutuo" en Manizales, Bogotá y Cúcuta. También se crearon por ese tiempo las "natilleras" en Antioquia, Valle y Cundinamarca, las cuales fueron predecesoras de los fondos de empleados y de algunas organizaciones promotoras de las ideas cooperativas en Colombia (Dansocial, 2005).

\section{Rafael Uribe Uribe}

Como presidente de Colombia, y con la consolidación de su pensamiento basado en el socialismo europeo,

\footnotetext{
7 Es una práctica muy común en estas regiones poner un dinero a circular por medio de aportes que hacen las personas con el fin de tener al final un incremento de estos con el interés dado por los préstamos.
}

Rafael Uribe Uribe consideró a sí mismo un nacionalista y se alejó del modelo de Estado liberal que el partido de similar nombre defendía en sus programas políticos, programas por los que él mismo había luchado. Entró a formar parte del gobierno conservador del general Rafael Reyes, en el cual desarrolló importantes gestiones de índole diplomática en pro del beneficio del país. Representó a Colombia ante los gobiernos de Argentina, Brasil y Chile y asistió a la Conferencia Panamericana de 1906.

A Uribe Uribe se le destaca como el precursor de las ayudas sociales a los trabajadores. A su vez, sostuvo la lucha por la creación de diversos estamentos de protección social en Colombia. Dio a la luz, en 1904, su popular discurso "El Socialismo de Estado", texto en el que mostraba al socialismo como medio para resolver los problemas que aquejaban al país; dicho discurso apoyaba, así, al sindicalismo y al corporativismo. En 1904, elabora un programa de socialismo liberal con intervención del Estado. Se proponía que este asumiera la reivindicación de los derechos de los trabajadores, abogaba por la creación de restaurantes populares, colonias de vacaciones, cajas y ahorros, sindicatos y cooperativas.

En 1931, se promulgó la primera ley cooperativa (Ley 134 de 1931). En 1932, con el Decreto Ley 874, dicta medidas para el fomento cooperativo. El Decreto 1339 reglamenta la Ley 134. En 1963, el Gobierno dicta el Decreto Ley 1598 que constituye el nuevo marco legal del cooperativismo colombiano. Con este Decreto Ley se inicia el auge del cooperativismo en Colombia (Marín, 2000). Mediante el Decreto 1587 de 1963 se establece la Superintendencia de Cooperativas. Posteriormente, por el Decreto 1629, del mismo año, se le da estructura y funciones a la Superintendencia y en 1968, por el Decreto 2059, se reglamenta el Decreto 1598 de 1963.

En 1981 la Ley 24 transforma la Superintendencia en Departamento Administrativo Nacional de Cooperativas. En diciembre 23 de 1988 la Ley 79 actualiza el régimen legal del cooperativismo y da nueva vida al sector cooperativo. En 1998, mediante la Ley 454, se transforma el Dancoop, Departamento Administrativo de Cooperativas, en el Departamento Administrativo Nacional de la Economía Solidaria Dansocial (Marín, 1991).

\section{Francisco Luis Jiménez}

Nació en 1902 en Granada, Antioquia (Colombia), realizó sus estudios primarios en la escuela de varones 
de Granada y luego sus estudios secundarios en el colegio nacional San José de Marinilla. Posteriormente estudió en la universidad de Antioquia, de la que se graduó como doctor en Derecho. Su tesis de grado sirvió de base para la elaboración de la primera ley cooperativa de Colombia, que es la Ley 134 de 1931. De ahí en adelante comenzó un trabajo dedicado al cooperativismo.

Mientras tanto, el mundo se debatía en grandes crisis. Francisco Luis Jiménez presenció, entre muchas, la gran crisis económica de 1930. Él siempre encontró en el cooperativismo la respuesta:

El trabajo produjo capital, sin embargo este lo dominó y valiéndose de la propiedad de los medios de producción de bienes y servicios, concluye que no lo hace propiamente para satisfacer las necesidades del hombre, sino para obtener una ganancia, una utilidad usurera y política que, quieran o no, ha dividido tanto a las naciones como a los hombres en unos que tienen mucho y otros que tienen poco, por lo que ha contribuido a que la pobreza sea más extensa y las necesidades menos posibles de ser solucionadas. No hay que olvidar que el cooperativismo nació precisamente como una protesta contra los abusos del capital, como una consigna: la defensa del consumidor, con una misión: la dignidad del trabajo y la libertad del trabajador. [...] Es necesario aprender del capitalismo, no propiamente para imitarlo, emularlo ni seguirlo en sus pasos; todo lo contrario, para poder vencerlo en su ideología, en sus pretendidos valores, situarlo en el campo del contrario (Citado por Giraldo Zuluaga, 2016, p. 64).

Desde 1930, Francisco Jiménez comenzó un gran trabajo para el surgimiento del sistema cooperativo colombiano. Lideró la fundación de más de 200 cooperativas, entre las cuales se encuentra la cooperativa de Oriente, la cooperativa de vivienda de Medellín, la cooperativa de cafeteros, seguros La Equidad, cooperativa Familiar, entre otras. También participó en la fundación de organismos cooperativos de segundo grado con el fin de agrupar a las cooperativas; es así que participó en la fundación de Ascoop (Asociación Colombiana de Cooperativas), de la que fue presidente por 20 años, y de Confecoop (Confederación de Cooperativas de Colombia). Luchó por la integración del cooperativismo colombiano y americano, lideró y presidió por 5 años la oca (Organización de Cooperativas de América).
Se presentó en escenarios colombianos y mundiales en los que izó la bandera de la cooperación y ayuda mutua. Esparció la semilla del cooperativismo por donde anduvo. En respuesta a la educación cooperativa que impartió, se tejieron instituciones solidarias que hoy siguen brindando bienestar social a las comunidades. "En el mundo del trabajo no importan los distingos de raza, de religión, de nacionalidad ni de idioma. Los cooperativistas reales, nos tratamos como hermanos en cualquier lugar del mundo" (Club de ensayos, 2013).

Falleció a los 106 años en el ciudad de Medellín. Siempre afirmó: “¡Existe otra vía! La estructura social de un hombre cooperador, para que todos logremos un pueblo cooperativo. Para que este logre un país, unos países, un mundo cooperativista". (Citado por Giraldo Zuluaga, 2016, 75). Encontró en el cooperativismo la vía para forjar un mundo mejor. Insistió en la cooperación, en la ayuda mutua, valores indispensables para un cooperativista. Forjó la idea de que todos somos cooperativistas, no solo los que suscriben un contrato con alguna cooperativa y aportamos al movimiento cooperativo desde nuestras acciones, cuando apoyamos al vecino, cuando cuidamos el medio ambiente, cuando apoyamos las causas nobles y buenas.

\section{Adán Puerto Sánchez}

A finales del siglo xix, y en las primeras décadas del siglo $\mathrm{xx}$, se expusieron en Colombia las primeras tesis vinculadas a la creación de instituciones especializadas sin ánimo de lucro. Fue el General Rafael Uribe (1904) quien, como presidente de la República, planteó la idea cooperativa. Luego, el padre Adán Puerto, por los años 20, la promueve en el oriente del país. Siguiendo el modelo que había visto en Europa, en 1931 se expide la primera Ley de Cooperativas con la influencia de grandes pensadores como Charles Gide y de la Escuela de Nimes, por lo que, desde su nacimiento, el cooperativismo colombiano se ajustó a la doctrina y principios promulgados por la ACI.

Las primeras cooperativas se orientaron al ahorro y crédito de tipo cerrado, pero surgieron luego otras de tipo multiactivo, casi todas con funciones de ahorro y crédito. Aunque algunas tesis universitarias tratan aspectos puntuales de la vida y obra de monseñor Puerto Sánchez, su mejor biografía la constituye un decreto del gobierno departamental de entonces 
(1977) y una editorial de Álvaro Gómez Hurtado en el periódico El Siglo (López, 1997).

\section{Conclusiones}

Es evidente que la economía solidaria aparece como consecuencia de las desigualdades sociales que se dieron durante las revoluciones del siglo XviII, revoluciones que sentaron las bases estructurales de la filosofía de la cooperación en los trabajadores de las organizaciones de la época. Lo anterior contribuyó al surgimiento de las primeras manifestaciones de cooperativismo como respuesta al inconformiso generalizado, su propósito era obtener una mejor distribución de los ingresos que permitiera fortalecer la calidad de vida de los trabajadores. De esta forma, se configura un modelo con principios de justicia y equidad que deben prevalecer como características de la economía abierta que en la actualidad ofrece un mercado de competencia imperfecta.

Con base en lo planteado en el texto, las economías solidarias deberían basar su desarrollo en la flexibilidad de los mercados y estar dispuestas al cambio. Todo esto mediante el desarrollo de estrategias que permitan enfrentar los desafíos propuestos por la apertura de mercados y el comportamiento de una política económica globalizada.

La economía solidaria es un modelo que propone ventajas para el mejoramiento de la calidad de vida de sus asociados, siempre y cuando su operatividad se base en la aplicación rigurosa de los principios filosóficos que lo enmarcan.

En el contexto actual, para la consolidación del proceso de paz en Colombia, dados sus principios, alcances y posibilidades en torno a la justicia, libertad, equidad y solidaridad, la economía solidaria se constituye como una herramienta apropiada para la implantación del posconflicto, pues involucra especialmente a la solidaridad, la unión y la equidad como principios que permiten el desarrollo sostenible de las regiones y la resolución de problemas comunes como los que ha vivido la sociedad colombiana desde hace varias décadas (problemas caracterizados por la violencia y el enfrentamiento). Ahora que se transita un camino hacia la paz, la solidaridad puede ser, en definitiva, un motor generador de espacios de entendimiento y cooperación que aporte a la solución definitiva que nos lleve a una paz duradera.

\section{Referencias}

Biografías y vidas. (2004-2016). Disponible en: http://www. biografiasyvidas.com/biografia/b/blanc.htm

Birnie, A. (1965). Historia Económica de Europa. Barcelona: Biblioteca Universal Miracle.

Club de ensayos. (2013). Disponible en: https://www.clubensayos.com/Negocios/NATURALEZA-DE-LA-COOPERATIVA/775951.html

Dansocial, Departamento administrativo nacional de la economía solidaria. (2005). Disponible en: http:// www.dane.gov.co/.

Diccionario de Economía Social. (2009). Disponible en: https://books.google.com.co

Edelmann, A. (1992). Los primeros 25 años de la Unión Internacional. Raiffeisen IRU, Courrier $\mathrm{N}^{\circ}$ 2. pp. 121

Funedas. Fundación Educación y Asesorías de Economía Solidaria. (2012, 37). Disponible en: http://www.funedas. org.co/ (tomado, septiembre, 2015).

Geertz, C. (1994). Conocimiento local: ensayos sobre la interpretación de las culturas. Barcelona: Paidós.

Geertz C.; Morris, D. y Taylor, Ch. Los usos de la diversidad (tomado, agosto, 2015). http://sobrefulanos.blogspot. com.co/2009/10/los-usos-de-la-diversidad-clifford. html.

Giraldo Zuluaga, D. (2016). Francisco Luis Jiménez: Padre del cooperativismo colombiano. Disponible en: http://www.desdegranada.com/index.php/columnistas/735-francisco-luis-jimenez-padre-del-cooperativismo-colombiano, p 64-75.

Jiménez, F. L. (2007). Memorias 1980-2006. Medellín: Editorial Confecoop.

Laidlaw, A. F. (2000). Las cooperativas en el año 2000. Bogotá: Ediciones Coocentros.

Lambert, P. (1961). La doctrina cooperativa. Buenos Aires: Ediciones Intercoop.

López, R. (21 de febrero de 1997). Editorial. El Tiempo.

Marín, E. (2000). Cooperativas, Solidaridad y otras Formas Asociativas. Medellín: Coimpresores.

Marx, C. (1884). Manifiesto Inaugural de la Asociación Internacional de los Trabajadores. Fundada el 28 de septiembre de 1864, en una Asamblea Pública celebrada en Saint Martin's Hall de Long Acre, Londres. Tomo I, 115-123 p. Disponible en: https://www.marxists.org/ espanol/m-e/1860s/1864fait.htm

Marx, C. (1970). El capital. México: Fondo de Cultura Económica. 
Mladenatz, G. (1980). Historia de las doctrinas cooperativas. Buenos Aires: Ediciones Intercoop.

Morris, D. (1968). El mono desnudo. Un estudio del animal humano. Barcelona: Orbis.

Oviedo, J. (2007). Fundamentos de la economía solidaria. Medellín: Jmar Ltda.

Parrila, A. (1989). Historia del cooperativismo en Puerto Rico. Santo Domingo: Nosotros.

Pineda, C. (1994). Cooperativismo mundial 150 años. Bogotá: Consultamerica.

Rojas, R. (1952). Tratado de cooperativismo mexicano. México: Fondo de Cultura Económica.

Taylor, C. (2003). El multiculturalismo y "la política del reconocimiento". Madrid: Fondo de Cultura Económica.

Uribe, C. (1993). Bases del cooperativismo. Bogotá: Fondo Nacional Universitario. 